

\title{
Cyclodextrin-Sandwiched Hexaphyrin Hybrids Side-to-Side Cavity Coupling Switched by a Temperature- and Redox-Responsive Central Device
}

Mickaël Ménand, Matthieu Sollogoub, Bernard Boitrel, Stéphane Le Gac

\section{To cite this version:}

Mickaël Ménand, Matthieu Sollogoub, Bernard Boitrel, Stéphane Le Gac. Cyclodextrin-Sandwiched Hexaphyrin Hybrids Side-to-Side Cavity Coupling Switched by a Temperature- and RedoxResponsive Central Device. Chemistry - A European Journal, 2018, 24 (22), pp.5804-5812. 10.1002/chem.201705958 . hal-01771516

HAL Id: hal-01771516

https://hal-univ-rennes1.archives-ouvertes.fr/hal-01771516

Submitted on 10 Sep 2018

HAL is a multi-disciplinary open access archive for the deposit and dissemination of scientific research documents, whether they are published or not. The documents may come from teaching and research institutions in France or abroad, or from public or private research centers.
L'archive ouverte pluridisciplinaire HAL, est destinée au dépôt et à la diffusion de documents scientifiques de niveau recherche, publiés ou non, émanant des établissements d'enseignement et de recherche français ou étrangers, des laboratoires publics ou privés. 


\title{
Cyclodextrin-Sandwiched Hexaphyrin Hybrids. Side-to-Side Cavity Coupling Switched by a Temperature and Redox Responsive Central Device
}

\author{
Mickaël Ménand, ${ }^{* a]}$ Matthieu Sollogoub, ${ }^{[\mathrm{a}]}$ Bernard Boitrel, ${ }^{[\mathrm{b}]}$ and Stéphane Le Gac ${ }^{*[\mathrm{~b}]}$ \\ Abstract: Access to allosteric enzyme mimics that ideally associate \\ communicating compartments for catalysis and regulation is still \\ challenging. Whereas a sandwich "cavity-catalyst-cavity" approach, \\ developed mainly with cyclodextrins and porphyrins, appears \\ promising, its counterpart with hexaphyrins featuring rich \\ conformation, aromaticity and coordination behavior has not been \\ prospected at all. We thus developed sandwich hybrids made of two \\ center against irreversible deactivation (e.g., formation of $\mu$-oxo \\ complexes), and (iii) strengthen a side-to-side allosteric \\ communication between the sandwiching cavities. Recently, \\ these kinds of architectures featuring "compartmentalized-and- \\ coupled" catalytic and regulation functions have been proposed \\ as blueprint for molecular Turing machines, capable of processing \\ information on a threaded polymer chain. ${ }^{[2]}$
}

\begin{abstract}
cyclodextrins triply-linked on each side of a hexaphyrin. The latter displays switchable oxidation states with interconvertible conformations (28 $\pi$ antiaromatic and $26 \pi$ aromatic each adopting rectangular and dumbbell forms). These four states are connected by two orthogonal switches under redox [aromaticity] and thermal [shape] control. It leads to twin compartmentalized confined spaces either locked or unlocked depending on the hexaphyrin conformation, the reversibility of the lock $\leftrightarrow$ unlock transition relying on the hexaphyrin aromaticity. The sandwiched heteroannulene thus behaves as an unprecedented dual-responsive double-latches device. Such hybrid systems open interesting perspectives in allosteric regulation of receptors, catalysts and machineries.
\end{abstract}

\section{Introduction}

The design of allosteric receptors and catalysts able to compete with the efficiency of allosteric enzymes remains a major challenge in supramolecular catalysis. ${ }^{[1]}$ An ultimate design for a synthetic allosteric catalyst would combine distinct recognition sites displaying asymmetrical confined environments conformationally connected. Each cavity would ensure substrates and effectors selection towards distinct catalytic and regulation functions. In this respect, macromolecular edifices integrating a catalytic center surrounded by two hosting sub-units in a sandwiched manner offer several inherent advantages (Figure 1a right): (i) they enable compartmentalization of catalytic and regulation functions, (ii) afford a protection of a catalytic metal

[a] Prof. M. Sollogoub and Dr. M. Ménand Sorbonne Université, UPMC Univ Paris 06, CNRS Institut Parisien de Chimie Moléculaire (IPCM), UMR 8232 4 place Jussieu, 75005 Paris (France)

E-mail: mickael.menand@upmc.fr

[b] Dr. B. Boitrel and Dr. S. Le Gac

Institut des Sciences Chimiques de Rennes, UMR CNRS 6226,

Université de Rennes 1

263 av. du General Leclerc, 35042 Rennes cedex (France)

E-mail: stephane.legac@univ-rennes1.fr

Supporting information for this article is available on the WWW under http://dx.doi.org/10.1002/chem.2017xxxxx. a)
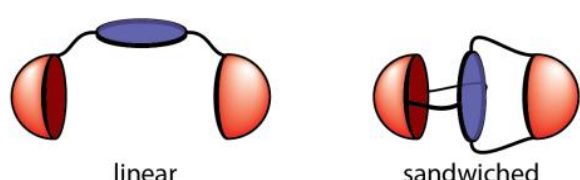

linear sandwiched

b)

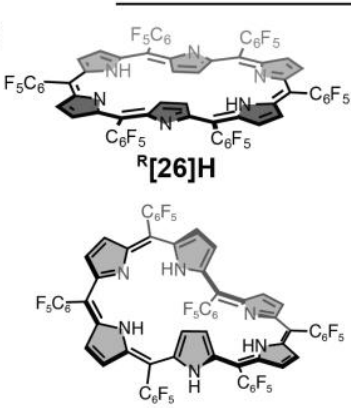

[28] H

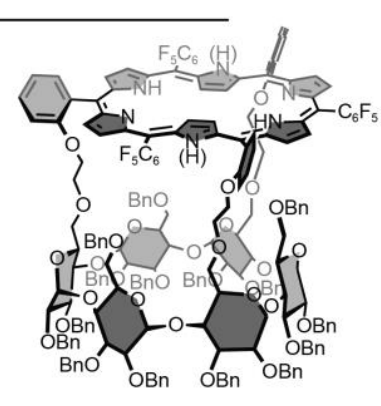

${ }^{\mathrm{R}}[26(28)] \mathrm{HCD}$ c)
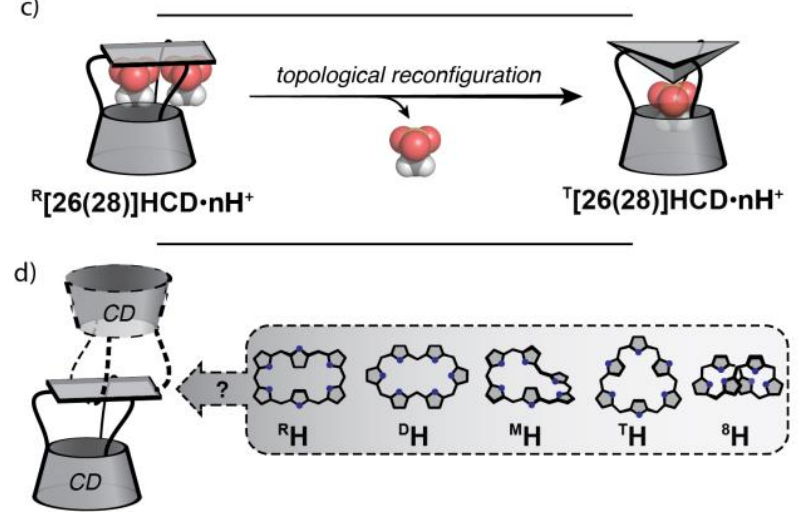

Figure 1. (a) Illustration of linear and sandwiched cavity-catalyst-cavity architectures. (b) Structures of the rectangular ${ }^{\mathrm{R}}[26] \mathrm{H}$, Möbius twisted M[28]H and hexaphyrin-cyclodextrin hybrids [26]HCD and [28]HCD (NH into brackets). (c) Rectangular-to-triangular topological reconfiguration of perprotonated [26] $\mathrm{HCD}_{4} \mathrm{H}^{+}$and [28] $\mathrm{HCD}^{2} \mathrm{H}^{+}$. (d) Simplified representation of the targeted cyclodextrin-sandwiched hexaphyrin hybrids (CDHCD) with the various conformations offered by hexaphyrins(1.1.1.1.1.1) (dashed inset). [26/28] indicate the number of electrons of the $\pi$-conjugated system.

However, access to sandwiched architectures is synthetically challenging, which explains why most of the "cavity-catalyst- 
cavity" associations (Figure 1a, left) involve singly linked cavities serving as anchoring points for a substrate presenting a specific domain to the catalytic site. As a result, these cavities rather operate a passive conformational restriction deprived of active allosteric regulation. ${ }^{[3]}$ Still, an effective sandwich approach involving cavities with distinct roles remains to be explored.

Cyclodextrins are well known to meet the enzyme pockets requirements in hybrid architectures. ${ }^{[4]}$ Their cyclic oligosaccharide skeleton provides naturally occurring chiral and water soluble structure with a confined hydrophobic environment. ${ }^{[5]}$ Besides, porphyrins are key catalysts extensively developed and used to support enzyme modelling studies. ${ }^{[6]}$ However, only a small number of sandwiched receptors/catalysts integrating either cyclodextrins and/or a central porphyrin have been reported and generally with modest yields. ${ }^{[7-12]}$ Furthermore, only a couple of examples from Naruta and Nolte groups showed allosteric communication between the porphyrin-separated cavities, owing to induced-fit guest inclusion processes. ${ }^{[11,12]}$ Although the porphyrin macrocycle displays some flexibility, we reasoned that such a sandwich design would be more modular with other porphyrinoids able to adopt major conformational changes, ${ }^{[13]}$ thus allowing more effective coupling of the cavities. Hexaphyrins are good candidates since they can adopt different conformations (rectangular [R], dumbbell [D], triangular [T], Möbius [M], figureeight [8], Figure 1d), ${ }^{[13 d, f]}$ with a possible control over their interconversion by external stimuli: (de)protonation, ${ }^{[14]}$ solvent polarity, ${ }^{[15]}$ temperature, ${ }^{[15 c],[16]}$ metal coordination, ${ }^{[17]}$ and more importantly, redox control of their $\pi$-conjugated circuits (i.e. $26 \pi$ vs. $28 \pi$ electrons: ${ }^{\mathrm{R}}[\mathbf{2 6}] \mathrm{H} /{ }^{\mathrm{M}}[28] \mathrm{H}$ Figure $1 \mathrm{~b}$, left). ${ }^{[15 b]}$ As such, hexaphyrins have a great, yet unexplored potential as switchable components in the design of molecular machineries. ${ }^{[18],[19]}$

In this context, we recently prepared a new type of hybrid edifices made of a hexaphyrin unit triply-linked on one side by a cyclodextrin (HCD, Figure 1b, right). ${ }^{[20]}$ This unique association generates a confined dissymmetrical environment between the rectangular hexaphyrin and the primary rim of the cyclodextrin. Interestingly, a rectangular-to-triangular shape shifting process was observed with protonated forms, allowing to tune the size and shape of the confined space and thus the molecular recognition properties of HCD (Figure 1c). ${ }^{[21]}$ In another recent example, a hexaphyrin triply-linked to a tris(2-aminoethyl)amine (tren) unit showed rectangular-to-Möbius conformational changes triggered by a cooperative two-guest binding process to a buried zinc metal ion. ${ }^{[22]}$ In spite of their triple linkage, the dynamic behavior of these two capped hexaphyrins stresses the high propensity of this heteroannulene to undergo profound and rapid conformational changes affording new types of adaptative molecular receptors. We thus envisioned that hexaphyrins doubly-capped by cyclodextrin units in a sandwich manner (CDHCD, Figure 1d) may undergo similar conformational reorganization allowing to change the shape of the sandwiched edifice, and thus the coupling of the cavities.

We therefore describe herein the first synthesis of doubly-capped hexaphyrins, affording compartmentalized-yet-coupled confined spaces matching a unique orthogonal control of the central hexaphyrin conformation and aromaticity.

\section{Results and Discussion}

\section{Synthesis}

The targeted cyclodextrin-sandwiched hexaphyrins (CDHCDs) possess an $(\mathrm{AB})_{3}$-type meso-substitution pattern. In the case of "unconstrained" hexaphyrins, this pattern is achieved by reacting an equimolar mixture of an aldehyde $A$ and a dipyrromethane $B .{ }^{[23]}$ The hexaphyrin frame is the major one among porphyrin and higher homologues, without scrambling (Scheme 1a, [3+3] macrocyclization). In the case of HCD hybrids, a related strategy consisting in the condensation of a cyclodextrin-tris-aldehyde platform (ACE pattern) with three equivalents of dipyrromethane (Scheme 1b top, [1+3] macrocyclization), afforded a hexaphyrin capped on one side by a cyclodextrin unit. ${ }^{[20]}$ This reaction was also attempted the other way, i.e. by reacting a cyclodextrin-trisdipyrromethane platform with three equivalents of aldehyde (Scheme 1b, bottom), leading to the same HCD hybrids. ${ }^{[24]}$ The present study investigates the ensuing strategy consisting in a

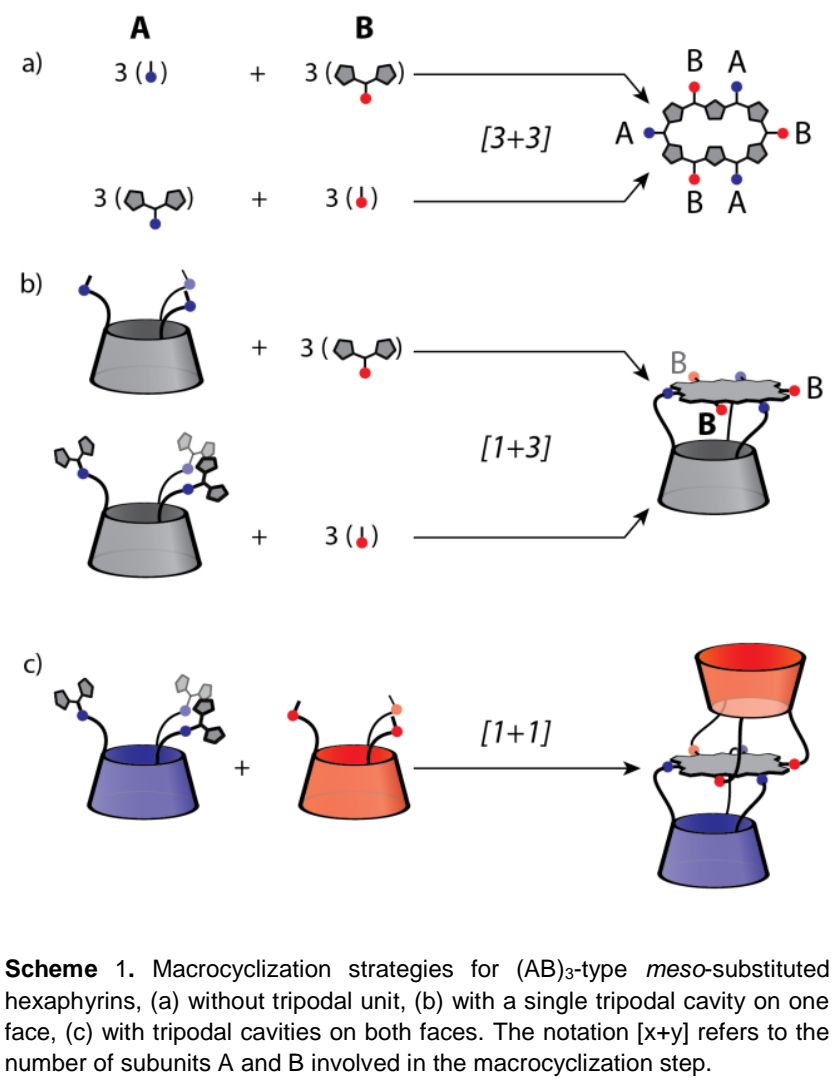
number of subunits $A$ and $B$ involved in the macrocyclization step. 




Scheme 2. Synthesis of $\mathrm{CD}[26] \mathrm{HCD}$ and $\mathrm{CD}[28] \mathrm{HCD}$ through a [1+1] condensation of 1 and 2. Representations of the equilibrated rectangular and dumbbell conformations are depicted in detailed and simplified views (perspective and top views in grey insets; $C_{2}$ symmetrically related parts colored in red and blue). Labelling of the two conformers is differing according to the location of the $C_{2}$ symmetry axis (see labels on the right).

$[1+1]$ macrocyclization between two complementary cyclodextrin platforms (Scheme 1c). The corresponding doubly-capped hexaphyrins are thus obtained through the condensation of the cyclodextrin-tris-aldehyde 1 and its related cyclodextrin-trisdipyrromethane adduct 2 (Scheme 2) ${ }^{[25]}$

The cyclodextrin-tris-aldehyde 1 was synthesized from the native a-cyclodextrin following a five steps procedure as previously described. ${ }^{[20]}$ Condensation of $\mathbf{1}$ with a large excess of pyrrole, catalyzed by trifluoroacetic acid (TFA), afforded the cyclodextrintris-dipyrromethane adduct 2 in $66 \%$ yield. The [1+1] macrocyclization between $\mathbf{1}$ and $\mathbf{2}$ was achieved in dichloromethane at $0.01 \mathrm{M}$ concentration using a catalytic amount of methanesulfonic acid $([\mathrm{MSA}]=0.002 \mathrm{M})$. The monitoring of the reaction by mass spectrometry indicated rapid completion (ca. 1h). Subsequent oxidation of the cyclodextrin-sandwiched hexaphyrinogens with 2,3-dichloro-5,6-dicyano-1,4benzoquinone (DDQ) followed by chromatography purification afforded the $C^{\mathrm{R}}[\mathbf{2 8}] \mathrm{HCD}$ hybrid (Scheme 2) which was however difficult to separate from oligomeric side products. To facilitate its purification, this $28 \pi$ form was further oxidized in its $26 \pi$ one by a second treatment with DDQ. Surprisingly, two fractions of different polarity were isolated by chromatography $(0.7 \%$ and $2.7 \%$ overall yield). HRMS (ESI-TOF) of both fractions afforded the same mass $\left([M+2 H]^{2+}: m / z \quad 2910.2570\right)$ corresponding to CD[26]HCD hybrids. As described below, their ${ }^{1} \mathrm{H}$ NMR spectra display different signatures corresponding to the rectangular 
(major) and the dumbbell (minor) conformers $\left(C^{\mathrm{R}}[26]\right.$ HCD and $\mathrm{CD}^{\mathrm{D}}[26] \mathrm{HCD}$ respectively, Scheme 2). Subsequent reduction of these fractions with $\mathrm{NaBH}(\mathrm{OAc})_{3}$ afforded their corresponding $28 \pi$ reduced forms with analytical purity $(81 \%$ yield for $\mathrm{CD}^{\mathrm{R}}[28] \mathrm{HCD}$, and $40 \%$ yield for $\mathrm{CD}^{\mathrm{D}}[28] \mathrm{HCD}$ following a specific pathway - vide infra). It is worth to note that conformational transitions occur between the rectangular and dumbbell CDHCDs for both oxidation states (Section 3), lengthening the purification steps. Although CDHCDs are obtained with modest yields, access to sandwiched expanded porphyrins is unprecedented and competes with strategies used for doubly-capped porphyrin edifices. ${ }^{[8 d],[9],[10]}$

\section{Characterization}

The UV-vis-NIR absorption spectra of these CDHCDs show strong similarities with those of the closely related HCDs (Figure $2 b, d)$. Indeed, the rectangular form of both families in their (28)26 $\pi$ states exhibit characteristic Hückel (anti)aromaticity. $\mathrm{CD}^{\mathrm{R}}[26] \mathrm{HCD}$ shows a strong Soret-like band $\left(\lambda_{\max }=568 \mathrm{~nm}\right)$ with four $Q$-like bands reaching the NIR region $\left(\lambda_{\max }=723,784,919\right.$ and $1050 \mathrm{~nm}$ ). This characteristic pattern denoting an aromatic character is almost superimposable to those of ${ }^{\mathrm{R}}[\mathbf{2 6}] \mathrm{HCD},{ }^{\mathrm{R}}[\mathbf{2 6}] \mathrm{H}$ and the Möbius aromatic ${ }^{\mathrm{M}}[\mathbf{2 8}] \mathrm{H}$ (Figure 2b,d). Conversely, CD $^{\mathrm{R}}$ [28]HCD displays a UV-vis spectrum typical of antiaromatic hexaphyrins in line with its related ${ }^{\mathrm{R}}[\mathbf{2 8}] \mathrm{HCD}$ (i.e. broad and smeared absorption bands at $\lambda_{\max }=488$ and $583 \mathrm{~nm}$, deprived of Q-like bands; Figure 2d). ${ }^{[2]}$ Compared to their rectangular isomers, the $26 \pi$ and $28 \pi$ dumbbell conformations exhibit broader UV-vis spectra of similar signatures. $C^{\mathrm{D}}[26] \mathrm{HCD}$ displays a less intense Soret-like band at $580 \mathrm{~nm}$ and broad Qlike bands between 700 and $1000 \mathrm{~nm}$, while CD $^{\mathrm{D}}$ [28]HCD displays large and smeared absorption bands at $\lambda_{\max }=500$ and $568 \mathrm{~nm}$. The erosion of intensity and broadening of the Q-like bands might arise from a distortion of the $\pi$-conjugation pathway of the hexaphyrin core (see below). ${ }^{[27]}$ Hence, $\mathbf{C D}^{\mathrm{D}}[26] \mathrm{HCD}$ and CD $^{\mathrm{D}}[28] \mathrm{HCD}$ also exhibit aromatic and antiaromatic character, respectively, but of weaker intensity compared to their rectangular forms.

The circular dichroism spectra of all CDHCD hybrids show Cotton effects involving the hexaphyrin Soret-like bands, indicating a clear chirality transfer from the surrounding cyclodextrins (Figure $2 \mathrm{a}, \mathrm{c})$. In the case of the rectangular conformations of singly- and doubly-capped hybrids, similar patterns are observed with bisignate signal splitting of the Soret-like bands broader for $28 \pi$ antiaromatic vs $26 \pi$ aromatic compounds. ${ }^{[28]}$ Besides, doublycapped rectangular hexaphyrin chromophores experience an enhanced chiral environment compared to their singly-capped ones (for ${ }^{\mathrm{R}}$ [26]HCD vs. CD ${ }^{\mathrm{R}}$ [26]HCD: $\Delta \varepsilon_{585} \simeq 40$ vs. $100 \mathrm{M}^{-1}$.cm ${ }^{1}$, Figure 2a; and for ${ }^{\mathrm{R}}[28] \mathrm{HCD}$ vs. $\mathrm{CD}^{\mathrm{R}}[28] \mathrm{HCD}: \Delta \varepsilon_{573} \simeq 30$ vs. $40 \mathrm{M}^{-1} \cdot \mathrm{cm}^{-1}$, Figure 2c). In stark contrast, the dumbbell conformation of CDHCD hybrids display less intense Cotton effects that are in line with the weaker absorption intensity and/or a less efficient chirality transfer.

Analysis of the ${ }^{1} \mathrm{H}$ NMR spectra $\left(\mathrm{CDCl}_{3}\right)$ of the four isolated CDHCDs allowed unambiguous structural and aromaticity characterization (Figure 3). The four CDHCDs display $C_{2}$ a)



c)

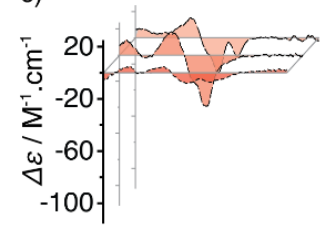

b)



d)

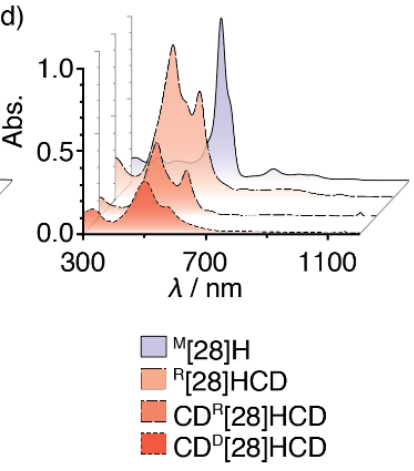

Figure 2. (a) Circular dichroism and (b) UV-vis-NIR spectra of ${ }^{\mathrm{R}}[26] \mathrm{H}$, ${ }^{\mathrm{R}}[26] \mathrm{HCD}, \mathrm{CD}^{\mathrm{R}}[26] \mathrm{HCD}$ and $\mathrm{CD}^{\mathrm{D}}[26] \mathrm{HCD}$ in $\mathrm{CH}_{2} \mathrm{Cl}_{2}$. (*) Contamination with traces of $C^{\mathrm{R}}$ [26]HCD. (c) Circular dichroism and (d) UV-vis-NIR spectra of ${ }^{\mathrm{M}}[28] \mathrm{H},{ }^{\mathrm{R}}[28] \mathrm{HCD}, \mathrm{CD}^{\mathrm{R}}[28] \mathrm{HCD}$ and $\mathrm{CD}^{\mathrm{D}}[28] \mathrm{HCD}$ in $\mathrm{CH}_{2} \mathrm{Cl}_{2}$. Blue spectra denote aromatic character and red spectra denote antiaromatic character.

symmetrical ${ }^{1} \mathrm{H}$ NMR spectra, the $C_{2}$ axes being located within the average plane of the hexaphyrins with different orientation according to the conformation. Whereas the rectangular species exhibit a transversal $C_{2}$ axis across the two proximal inverted pyrroles ( $\pi 2 / \pi 5$ inward), the dumbbell ones exhibit a longitudinal $C_{2}$ axis across the two distal pyrroles located on the short sides ( $\pi 2 / \pi 5$ outward, Scheme 2 , simplified views in inset). The NMR spectra display two characteristic sets of signals, a first one accounting for the two $C_{2}$-symmetrically related cyclodextrins $(2 \times$ 6 different glucose units [A to F], 2-6 ppm crowded region) and a second one spanning over $\sim 25 \mathrm{ppm}$ corresponding to half of the hexaphyrin $(2 \times 6 \beta$-pyrrolic protons and $2 \times 1$ or $2 \mathrm{NH}$ protons $)$. For the sake of conciseness, NMR description focuses on characteristic groups of protons discussed hereafter.

\section{(i) rectangular species}

The hexaphyrin protons of the doubly-capped hybrids experience the same field effects as their singly-capped homologues (Figure 3 , b vs. a and e vs. f, red and blue boxes). The ${ }^{1} \mathrm{H}$ NMR spectrum of $C^{\mathrm{R}}$ [26]HCD (Figure $3 \mathrm{~b}$ ) displays two upfield shifted singlets ( $\pi$-in: -3.35 and $-3.21 \mathrm{ppm}$ ) and four downfield doublets ( $\pi-$ out: 8.42 to $9.34 \mathrm{ppm}$ ) corresponding to the four inward $\beta$-pyrrolic protons ( $\pi 2$ and $\pi 5)$ and the eight outward $\beta$-pyrrolic ones $(\pi 1$, $\pi 3, \pi 4$, and $\pi 6$ ) respectively. The reverse distribution is observed for $\mathrm{CD}^{\mathrm{R}}$ [28]HCD (Figure 3e), with the two singlets shifted at 20.43 and $20.01 \mathrm{ppm}(\pi-i n)$ and the four doublets ranging from 2.49 to $3.12 \mathrm{ppm}$ ( $\pi$-out). These chemical shifts witness pronounced diatropic and paratropic ring current for respectively the $26 \pi$ and $28 \pi$ conjugated states, shielding(/deshielding) the inside and 


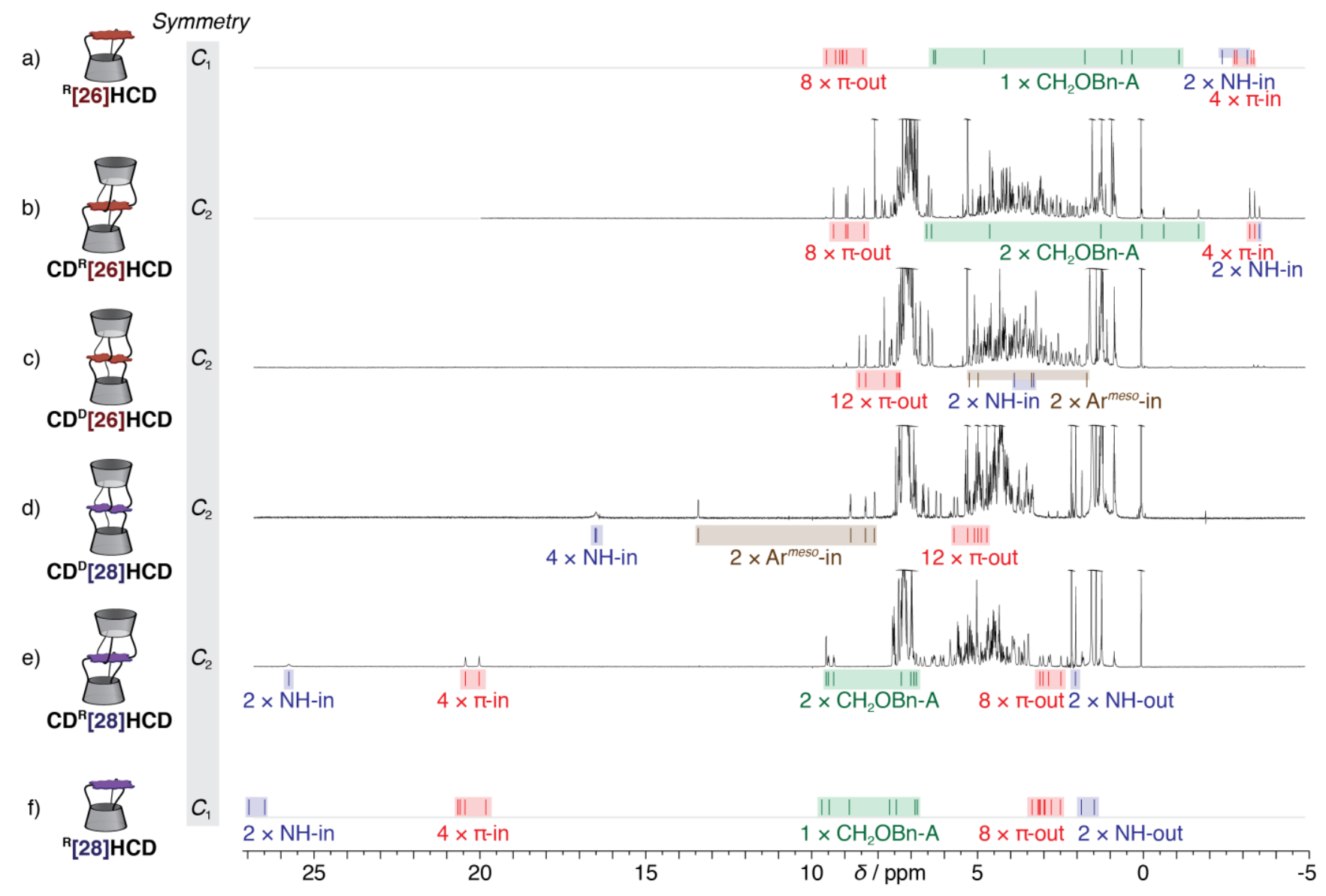


selected signals of the four CDHCD species and their HCD analogues ( $a$ and $f$ ) are depicted as ticks in coloured boxes.

deshielding(/shielding) the outside of the hexaphyrin frame. In conjunction with UV-vis absorption spectra, these NMR observations confirm the respective aromatic and antiaromatic characters of $C D^{\mathrm{R}}[\mathbf{2 6}] \mathrm{HCD}$ and $C D^{\mathrm{R}}[\mathbf{2 8}] \mathrm{HCD}$ hybrids.

In addition, the chemical shifts of the sandwiching cyclodextrins follow the same trend as those of HCDs. ${ }^{[20]}$ Notably, the marked characteristic shifting of the protons belonging to the O- 6 benzyl group of unit $\mathrm{A}$ (" $\mathrm{CH}_{2} \mathrm{OBn}-\mathrm{A}$ ", Figure 3 , b vs. a and e vs. f, green boxes) indicates an offset of the cavities from the center of the hexaphyrin, the latter protruding over the two $C_{2}$-symmetrically related $A$ glucose units (Scheme 2, cartoon in inset). ${ }^{20]}$ This particular topology inherently associates an NNCC coordination box to a specific cavity. Indeed, the two faces of a given NNCC coordination box experience different environments: one axial coordination is hindered to some extent by the cyclodextrin's wall whereas the opposite axial coordination is surrounded by a confined space (see below). As a consequence of the $C_{2^{-}}$ symmetry of CDHCDs, the "left" and "right" NNCC coordination sites are thus coupled to divergent cavities ("bottom" and "top"), offering a unique opportunity to study potential side-to-side communication across the hexaphyrin through allosteric events.

\section{(ii) dumbbell species}

In the case of the dumbbell CDHCDs (Figure 3c,d), the twelve $\beta$ pyrrolic protons (two singlets and four doublets) are located at the periphery of the hexaphyrin and experience deshielding(/shielding) due to diatropic//paratropic) ring currents

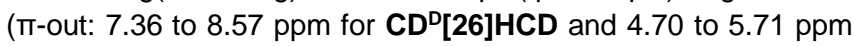
for $\mathrm{CD}^{\mathrm{D}}$ [28]HCD). The dumbbell conformation is also supported by the characteristic shifts of the two introverted meso-aromatic substituents located in the pinched region of the macrocycle (Figure 3c,d, brown boxes). These aromatic protons are unevenly shielded(/deshielded) with a strong effect towards the protons in ortho position to the hexaphyrin link $\left[\delta\left(\mathrm{H}_{0}{ }^{\mathrm{H}}\right)=1.71 \mathrm{ppm}\right.$ for $C^{\mathrm{D}}[26] \mathrm{HCD}$ and $13.42 \mathrm{ppm}$ for $\left.\mathbf{C D}^{\mathrm{D}}[28] \mathrm{HCD}\right]$. This indicates that the introverted meso-aromatic groups stand almost orthogonally to the hexaphyrin mean plane. The inner orientation is expected to generate important steric hindrance, likely compensated by a distortion of the hexaphyrin, and this may explain the weaker diatropic and paratropic ring currents of the dumbbell species. ${ }^{[29]}$ Thus, in accordance with the UV-vis spectra, a marked deviation from planarity likely reduces effective $\pi-$ 


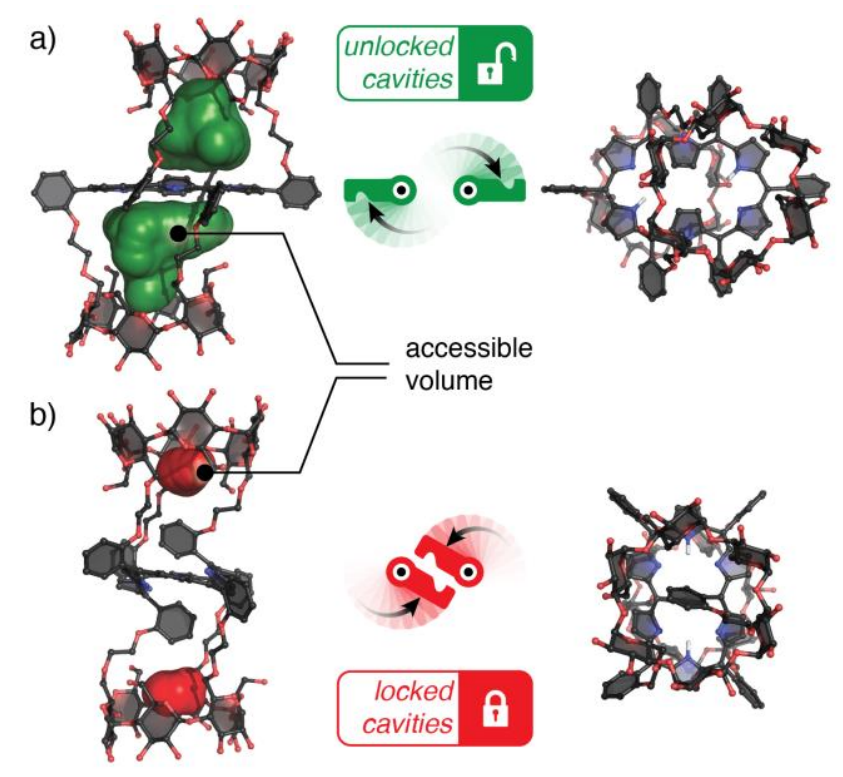

Figure 4. Side view and apical view from the cyclodextrin secondary rim of the optimized geometry of (a) $C^{\mathrm{R}}[26] \mathrm{HCD}$ and (b) $\mathrm{CD}^{\mathrm{D}}[26] \mathrm{HCD}$ (Avogadro software, UFF parameters; benzyl groups were omitted for the modeling). The calculated Connolly solvent-accessible surface areas are depicted in green and red. The latches cartoons at the center illustrate the locking/unlocking principle.

conjugation leading to a "weakening" of both aromaticity $\left(C^{\mathrm{D}}[26] \mathrm{HCD}\right)$ and antiaromaticity $\left(\mathrm{CD}^{\mathrm{D}}[28] \mathrm{HCD}\right)$. In contrast to the rectangular CDHCDs, no evidence was observed for an offset of the sandwiching cyclodextrins vs the dumbbell [26/28] hexaphyrins.

The molecular modelling of the rectangular and dumbbell conformers (26 $\pi$ oxidation state) showed no significant variation with the geometric features deduced from UV-vis and NMR analysis (Figure 4). Connolly solvent-accessible surfaces were calculated, evidencing a major difference in hosting potential. For $\mathrm{CD}^{\mathrm{R}}[26] \mathrm{HCD}$, the hexaphyrin is sandwiched by two identical and dissymmetrical confined spaces, each delineated by the hexaphyrin plane, the three linkers, and the cyclodextrin primary rim (green color, Figure 4a). These confined spaces are roughly similar to that of ${ }^{\mathrm{R}}[\mathbf{2 6}] \mathrm{HCD}$, large enough to include two molecules of $\mathrm{MSA}^{-[20],[21]}$ In contrast, the self-inclusion of two meso-aryl groups in the dumbbell conformation severely restricts this solvent-accessible volume (red color, Figure 4b). Although the cyclodextrin cavities are preserved, their "direct" interaction with the hexaphyrin is no longer possible. Thus, the meso-aryl groups act as latches locking or unlocking (dumbbell or rectangular conformation respectively) the access to both the hexaphyrin core and the associated confined spaces. Were transitions between these conformations to be controlled, the central hexaphyrin would become a switchable device for tuning the CDHCD hostguest properties in a coupled manner.

\section{Conformational switching}

As stated in Section 1, the separation of the rectangular and dumbbell conformations of CDHCDs was made difficult because of conformational transition between the two forms. We thus investigated the dynamic behavior of these conformations through ${ }^{1} \mathrm{H}$ NMR spectroscopy in $\mathrm{CDCl}_{3}$. VT-NMR of $\mathrm{CD}^{\mathrm{R}}[26] \mathrm{HCD}$ and $\mathrm{CD}^{\mathrm{D}}[26] \mathrm{HCD}(230$ to $330 \mathrm{~K}$ ) showed little changes of their chemical shifts indicating minor deviation from the rectangular and dumbbell conformations over the explored range of temperature (SI). However, for each conformer, traces of the other one were produced at high temperature $(330 \mathrm{~K})$ during the analysis. Evolution of these separated samples $\left(C^{\mathrm{R}}[26] \mathrm{HCD}\right.$ or $\left.\mathrm{CD}^{\mathrm{D}}[26] \mathrm{HCD}\right)$ for a prolonged period of time at $330 \mathrm{~K}$ allowed to reach the same ratio of the two conformers, evidencing thermodynamic equilibrium $(R / D=70: 30$, Figure $5 \mathrm{~b}$ and $\mathrm{SI})$. In contrast, heating a pure sample of $\mathrm{CD}^{\mathrm{R}}[\mathbf{2 8}] \mathrm{HCD}$ at $330 \mathrm{~K}$ in $\mathrm{CDCl}_{3}$ for 15 hours did not produce any trace of $C^{\mathrm{D}}$ [28]HCD conformer, whereas heating $C^{\mathrm{D}}[\mathbf{2 8}] \mathrm{HCD}$ in the same conditions led progressively to a full conversion of the dumbbell form into the rectangular one (Figure $5 \mathrm{a}$ and $\mathrm{SI}$ ). Accordingly, the two conformers are not in equilibrium but rather correspond to kinetic (dumbbell) and thermodynamic (rectangular) products.

The kinetic profile of the latter transformation was then examined monitoring the time dependent conversion of $\mathbf{C D}^{\mathrm{D}}$ [28]HCD into $C^{\mathrm{R}}[28] H C D$. Surprisingly, the transformation did not follow a first order rate law, the kinetic profile being "too linear" (Figure $5 \mathrm{c}$ and $\mathrm{SI})$. Instead, the data better fitted with a putative model involving a catalytic step with a catalyst loading estimated at $0.5 \mathrm{~mol} \%(\mathrm{SI})$. Further experiments should be performed to identify the nature of the expected catalyst and its mode of action. ${ }^{[30]}$

Table 1. Kinetic constants $\left(k / h^{-1}\right)$ and activation free energies $\left(\Delta G^{\ddagger} /\right.$ kcal.mol $\left.{ }^{-1}\right)$ for $\mathrm{CD}^{\mathrm{D}}[26] \mathrm{HCD} \rightleftarrows \mathrm{CD}^{\mathrm{R}}[26] \mathrm{HCD}$ equilibrium.

\begin{tabular}{lccccc|}
\multicolumn{1}{c}{ Solvent } & $\mathrm{T}(\mathrm{K})$ & \multicolumn{2}{c}{$\mathrm{D} \rightarrow \mathrm{R}^{[\mathrm{a}]}$} & \multicolumn{2}{c|}{$\mathrm{R} \rightarrow \mathrm{D}^{[\mathrm{b}]}$} \\
\cline { 3 - 6 } & & $k_{1}$ & $\Delta \mathrm{G}^{\ddagger}$ & $k-1$ & $\Delta \mathrm{G}^{\ddagger}$ \\
\hline $\mathrm{CDCl}_{3}$ & 330 & 0.87 & 24.9 & 0.27 & 25.6 \\
$\mathrm{THF}-d_{8}$ & 310 & 0.43 & 23.8 & 0.17 & 24.3 \\
\hline
\end{tabular}

[a] Dumbbell to rectangular pathway; [b] Rectangular to dumbbell pathway.

Table 2. Thermodynamic values $\left(\mathrm{kcal}^{\mathrm{mol}}{ }^{-1}\right)$ extracted from the van't Hoff plots of $C^{D}[26] H C D \rightleftarrows D^{R}[26] H C D$ equilibrium.

\begin{tabular}{|lcccc|}
\hline Solvent & $\Delta \mathrm{H}$ & $\Delta \mathrm{S}$ & $-\mathrm{T} \Delta \mathrm{S}^{[\mathrm{a}]}$ & $\Delta \mathrm{G}^{\text {[a] }}$ \\
\hline $\mathrm{CDCl}_{3}$ & $-6.8 \pm 0.5$ & $-0.019 \pm 0.001$ & 6.3 & -0.5 \\
THF- $d_{8}$ & $-7.0 \pm 0.6$ & $-0.021 \pm 0.002$ & 7.0 & 0.0 \\
\hline [a] Calculated at $330 \mathrm{~K}$. & & & \\
\hline
\end{tabular}




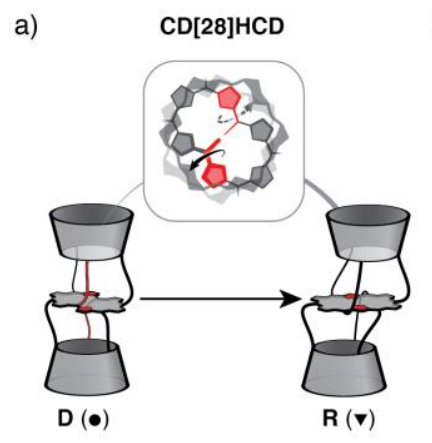

c)



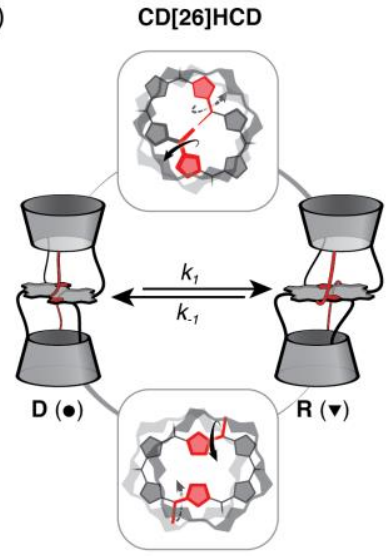

e)



d)



Figure 5. Simplified illustrations of $(a)$ the $D \rightarrow R$ conversion of $C D[28] H C D$ and (b) the $\mathrm{D} \rightleftarrows \mathrm{R}$ equilibrium of $\mathrm{CD}[26] \mathrm{HCD}$. Rotation of the pyrroles for both transformations are depicted in the insets. Kinetic plots following the time dependant concentration variations of $D(\bullet)$ and $R(\boldsymbol{\nabla})$ forms in $\mathrm{CDCl}_{3}$ at 330 $\mathrm{K}$ for (c) $C D$ [28]HCD and (d) CD[26]HCD (fitting curve in red). (e) VT- ${ }^{1} \mathrm{H}$ NMR stacks ( $600 \mathrm{MHz}$, sealed tube) of $\mathrm{R}$ and $\mathrm{D}$ equilibrated mixture of $\mathrm{CD}$ [26]HCD from 330 to $360 \mathrm{~K}$ in $\mathrm{CDCl}_{3}$ (red box) and THF-d (blue box). The regions selected show $\pi-1 / 3^{A r-i n}(D: \bullet)$ and $\pi-4 / 6^{S}(R: \nabla)$ evolution (labelling in Scheme 2).

Conversely, the kinetic profiles of the equilibration pathways concerning $C^{\mathrm{D}}[26] \mathrm{HCD}$ and $\mathrm{CD}^{\mathrm{R}}[26] \mathrm{HCD}(\mathrm{D} \rightleftarrows \mathrm{R}$ starting from $\mathrm{D}$ or R) fitted well by a first-order rate law (Figure $5 \mathrm{~d}$ and $\mathrm{SI}$ ). The corresponding kinetic constants ( $k_{1}$ and $k_{-1}$ respectively) measured in both $\mathrm{CDCl}_{3}$ and THF- $d_{8}$ allowed to calculate the free energies of activation (Table $1, \Delta G^{\ddagger}, S I$ ). Indeed, the isomerization pathway between the rectangular and dumbbell forms involves a formal in/out inversion of two opposite pyrroles (red pyrroles in Figure $5 \mathrm{~b}$ ) assisted by $\mathrm{NH}$ hydrogen bonding. Concomitantly, their neighboring meso-aromatic groups facing each other undergo a reverse out/in inversion. The energy barriers of these transformations (Table $1, \Delta \mathrm{G}^{\ddagger}{ }_{330}=23.8$ to 25.6 $\mathrm{kcal} . \mathrm{mol}^{-1}$ ) are of the same amplitude as the one previously determined for the related singly-capped ${ }^{\mathrm{R}}[\mathbf{2 6}] \mathrm{HCD}\left(\Delta \mathrm{G}^{\ddagger}{ }_{360}=23.3\right.$ $\left.\mathrm{kcal} . \mathrm{mol}^{-1}\right)$. This latter undergoes a so-called isomorphic fluxionality converting the rectangular conformation into another degenerate rectangular one through the formal rotation of four pyrroles. ${ }^{[20]}$ The energy barriers of the $D \rightleftarrows R$ equilibrium are sufficiently high to allow the isolation of each conformer at room temperature and keep them kinetically stable at low temperature $\left(4^{\circ} \mathrm{C}\right)$.

We then examined the equilibrated proportion of the two conformers between 330 and $360 \mathrm{~K}$ in $\mathrm{CDCl}_{3}$ and THF- $d_{8}$ (Figure 5e). ${ }^{[31]}$ Interestingly, in both solvents, the $D \rightleftarrows R$ equilibrium is pushed towards the dumbbell conformer with increasing

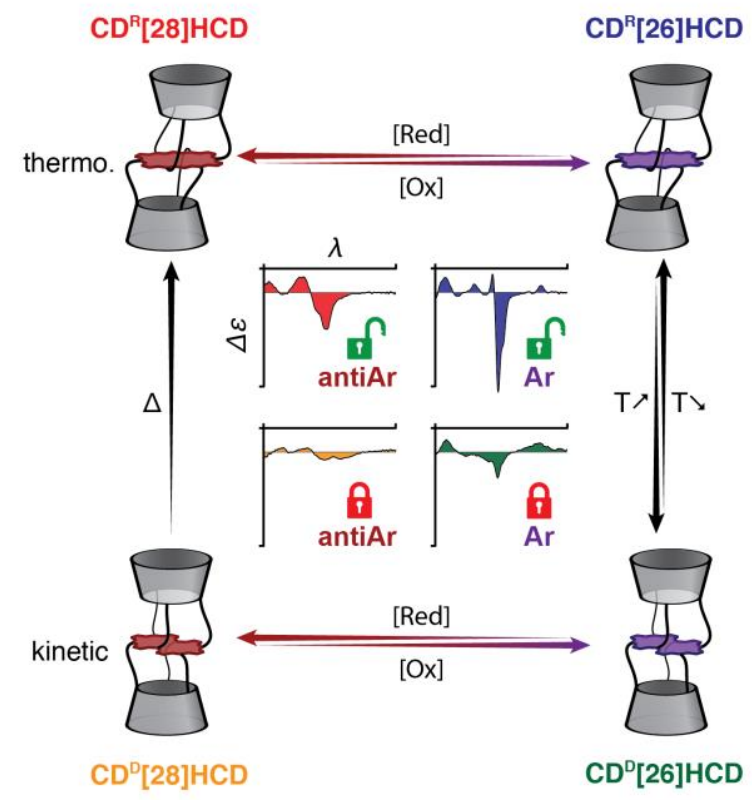

Figure 6. Global network showing the pathways between the four states of $\mathrm{CDHCD}$ and the triggering action. Individual circular dichroism signatures are depicted in the middle in association with the locking and aromatic states.

temperature. The effect is more pronounced in THF- $d_{8}$ with R/D ratios at $360 \mathrm{~K}$ up to $30: 70$ vs $50: 50$ in $\mathrm{CDCl}_{3}$. The equilibrium constants $(K=[R] /[D])$ derived from the measured ratios allowed to draw the van't Hoff plot (SI) and determine the energy parameters engaged in the rearrangement (Table 2). The corresponding enthalpic gain is probably arising from a more efficient double hydrogen bonding network (hexaphyrin $\mathrm{N}$-core) in the less distorted rectangular conformation, while the entropic cost might be ascribed to the higher capability of the rectangular conformer to encapsulate solvent molecules (locked vs. unlocked cavities, Figure 4). Remarkably, this thermal tuning of the hexaphyrin conformation transforms CDHCD architecture into the first device in which the dynamical control of the open and closed states is performed by an expanded porphyrin.

Once these dynamic processes analyzed, we devised a strategy to access the $C^{\mathrm{D}}[\mathbf{2 8}] \mathrm{HCD}$ isomer (kinetic product) otherwise difficult to obtain through direct synthesis. The strategy involves an equilibration of the $26 \pi$ isomers at high temperature followed by a rapid quenching and a reduction of the dumbbellenriched mixture (SI). Hence, $\mathrm{CD}^{\mathrm{R}}$ [26]HCD was heated at $90^{\circ} \mathrm{C}$ for $15 \mathrm{~min}$ in THF pushing the ratio towards the dumbbell conformer. A subsequent rapid cooling from $90^{\circ} \mathrm{C}$ to $-78^{\circ} \mathrm{C}$ allowed to freeze the equilibrium and kinetically trap the dumbbellenriched mixture $(R / D \approx 30: 70$ [NMR ratio, SI]). The latter was further reduced at $0^{\circ} \mathrm{C}$ with tetra- $n$-butylammonium borohydride $\left(\mathrm{TBABH}_{4}\right)$ affording the corresponding mixture of $28 \pi$ conformers with a ca. 1:1 dumbbell/rectangular ratio. Upon separation, $\mathrm{CD}^{\mathrm{D}}[28] \mathrm{HCD}$ was isolated in $40 \%$ yield (analytical sample). The 
combination of the temperature-controlled equilibrium of $26 \pi$ conformers with their $28 \pi$ redox conversions not only gives an access in reasonable yield to kinetic species $\left(\mathrm{CD}^{\mathrm{D}}[\mathbf{2 8}] \mathrm{HCD}\right)$ but also delineate a global reaction network connecting all CDHCDs as shown below.

\section{Global reaction network and one-way cycling}

Figure 6 summarizes the aromaticity and conformational changes connecting the four CDHCDs. On the one hand, the $28 \pi$ and $26 \pi$ states are redox interconvertible regardless of their conformation. This allows independent antiaromatic-aromatic transitions (left/right). On the other hand, transitions between the locked and unlocked states (D/R conformations) depend on the aromaticity of the hexaphyrin (top/bottom). Both states of the $26 \pi$ aromatic hybrids are in equilibrium and temperature controlled, whereas those of the $28 \pi$ antiaromatic hybrids are irreversibly connected (kinetic locked state and thermodynamic unlocked state).

Thus, aromaticity and conformational transitions can be orthogonally addressed (redox vs. temperature control) offering an interesting combination for the development of multiaddressable allosteric receptors. Obviously, a mutual influence of such a reaction network with hosting and coordination properties of the CDHCD hybrids is expected. In addition, these four hybrids exhibit markedly different chiroptical signatures in circular dichroism (Figure 6), offering an additional opportunity for orthogonal chiroptical switches. ${ }^{[18 b]}$

To exemplify these orthogonal transitions, we attempted to realize a one-way cycle over the global reaction network (Figure 7 and $\mathrm{SI})$. The following experiment was monitored by ${ }^{1} \mathrm{H}$ NMR spectroscopy in a sealed tube: first, $C^{\mathrm{R}}[28] \mathrm{HCD}$ was fully converted to $C^{\mathrm{R}}[\mathbf{2 6}] \mathrm{HCD}$ by treatment with $\mathrm{DDQ}$ (Figure 7a,b); then, equilibration following the heating/freezing procedure described above, afforded $\mathbf{C D}^{\mathrm{D}}[\mathbf{2 6}] \mathrm{HCD}$ as the major species $\left(R / D=40: 60\right.$, Figure 7c); subsequent reduction with $\mathrm{TBABH}_{4}$ gave $C D^{D}[28] H C D$ without modification of the ratio $(R / D=40: 60$, Figure $7 \mathrm{~d}$ ); finally, heating the sample converted the last mixture into the initial $C^{\mathrm{R}}[\mathbf{2 8}] \mathrm{HCD}$ as a single product (Figure 7e). This process corresponds to the following sequential transitions: antiaromatic/unlocked -> aromatic/unlocked -> aromatic/locked $>$ antiaromatic/locked -> antiaromatic/unlocked.

\section{Conclusions}

In conclusion, the grafting of a cyclodextrin unit on each side of a hexaphyrin, leading to 2:1 sandwich edifices, has been successfully realized. Such doubly-capped hybrid structures are unprecedented with expanded porphyrins.

On the one hand, the CDHCDs share similar properties with their parent 1:1 HCD hybrids: (i) the hexaphyrin preferably adopts a rectangular shape for both the $26 / 28 \pi$-conjugated states. Thus, aromatic and antiaromatic compounds, featuring markedly different chiroptical properties, are accessible and interconvertible; (ii) the cyclodextrin units are offset from the hexaphyrin center, in opposite directions, and thus specifically coupled to adjacent NNCC coordination sites. This particular

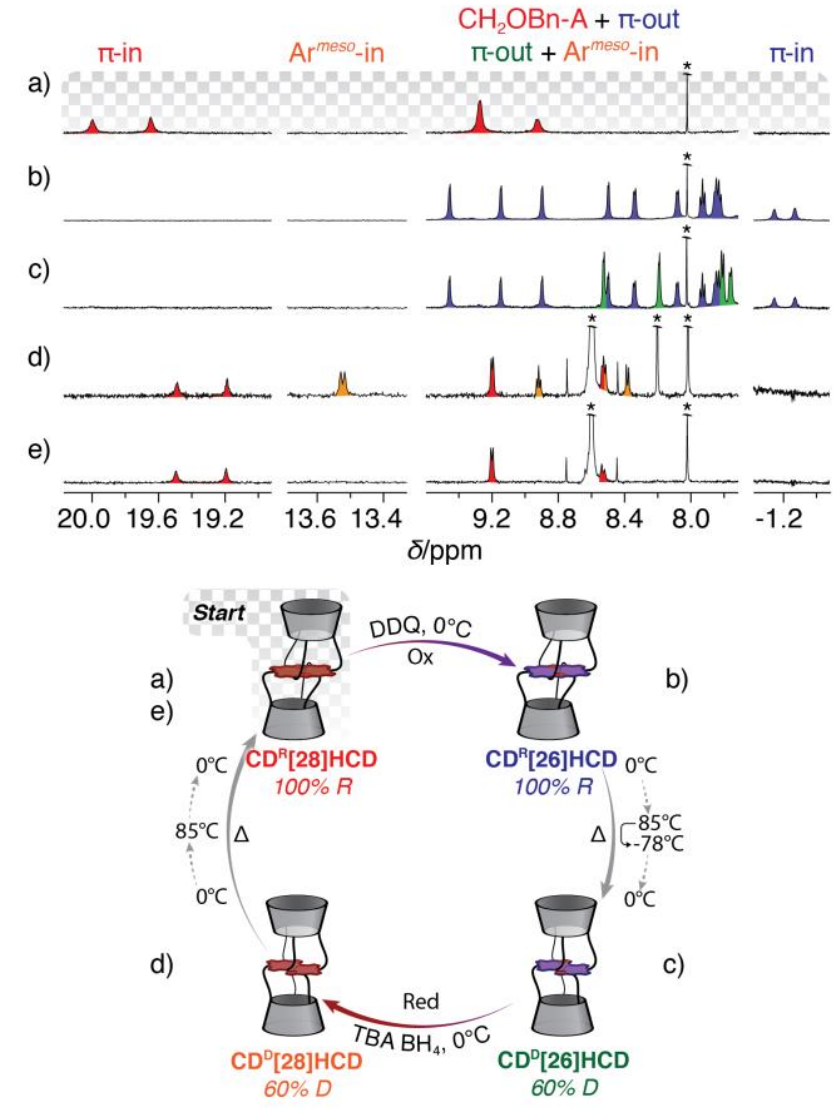

Figure 7. One screw cycle over the four CDHCDs (bottom), monitored by ${ }^{1} \mathrm{H}$ NMR spectroscopy (top; THF-d8, 276 K). Conditions: see the SI. $\left(^{*}\right)$ residual solvents and impurities.

arrangement affords two apical confined spaces, both compartmentalized and connected by the central hexaphyrin unit. On the other hand, CDHCDs exhibit unique conformational features characterized by the dumbbell conformation observed for both 26/28 $\pi$-conjugated states. A second set of aromatic and antiaromatic compounds is thus accessible with, again, different chiroptical properties. In addition, the dumbbell conformations severely restrict the confined spaces due to the introversion of two meso-aromatic groups.

Four different CDHCDs are accessible and connected through a reaction network orthogonally addressed by temperature changes (dumbbell-to-rectangular transitions triggering locked-unlocked

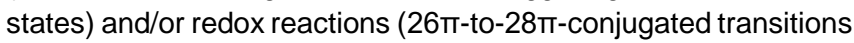
controlling aromaticity-antiaromaticity and thus the reversibility of the above conformational transitions). Remarkably, a one-way cycle through the reactions network allowed the sequential transition over the four CDHCDs. These architectures are thus switchable devices controlled by a thermal and redox responsive central hexaphyrin unit. The associated conformational reconfigurations of the whole structure connect the cavities in different manners. Hosting and coordination properties of these various hybrids are currently under investigation with a particular interest towards their mutual influence to target multi-addressable allosteric receptors and catalysts. 


\section{Experimental Section}

Full experimental details and spectral data are given in the Supporting Information.

\section{Acknowledgements}

We are grateful to the Agence Nationale de la Recherche for financial support (ANR research program PRALLOCAT, ANR-16CE07-0014).

Keywords: Aromaticity • conformational analysis • cyclodextrin • hexaphyrin $\cdot$ molecular device

[1] a) L. Kovbasyuk, R. Krämer, Chem. Rev. 2004, 104, 3161-3188; b) T. W. Traut, Allosteric Regulatory Enzymes, Springer Science \& Business Media, Boston, MA, 2008; c) M. J. Wiester, P. A. Ulmann, C. A. Mirkin, Angew. Chem. Int. Ed. 2011, 50, 114-137; d) C. Kremer, A. Lützen, Chem. Eur. J. 2013, 19, 6162-6196; e) V. Blanco, D. A. Leigh, V. Marcos, Chem. Soc. Rev. 2015, 1-30.

[2] S. Varghese, J. A. A. W. Elemans, A. E. Rowan, R. J. M. Nolte, Chem. Sci. 2015, 6, 6050-6058.

[3] a) R. Breslow, Y. Huang, X. Zhang, J. Yang, Proc. Natl. Acad. Sci. USA 1997, 94, 11156-11158; b) R. R. French, J. Wirz, W.-D. Woggon, Helv. Chim. Acta 1998, 81, 1521-1527.

[4] a) R. Breslow, Ed., Artificial Enzymes, Wiley-VCH, Weinheim, 2006; b) Y. Liu, Y. Chen, Acc. Chem. Res. 2006, 39, 681-691; c) A. J. Kirby, F. Hollfelder, From Enzyme Models to Model Enzymes, Royal Society of Chemistry, 2009

[5] I. Tabushi, Acc. Chem. Res. 1982, 15, 66-72.

[6] a) B. Meunier, Chem. Rev. 1992, 92, 1411-1456; b) R. A. Decréau, J. P. Collman, A. Hosseini, Chem. Soc. Rev. 2010, 39, 1291-1301.

[7] For cavitand-porphyrinoid hybrids, see: Ü. İşci, Z. Şahin, F. Dumoulin, V. Ahsen, in Handbook of Porphyrin Science, World Scientific Publishing Company, 2016, pp. 165-297.

[8] For cyclodextrin-sandwiched porphyrin, see: a) I. Tabushi, Y. Kuroda, K. Shimokawa, J. Am. Chem. Soc. 1979, 101, 1614-1615; b) Y. Kuroda, Y Sasaki, Y. Shiroiwa, I. Tabushi, J. Am. Chem. Soc. 1988, 110, 40494050 ; c) Y. Kuroda, T. Hiroshige, T. Sera, Y. Shiroiwa, H. Tanaka, H. Ogoshi, J. Am. Chem. Soc. 1989, 111, 1912-1913; d) Y. Kuroda, T. Hiroshige, T. Sera, H. Ogoshi, Carbohydr. Res. 1989, 192, 347-350; e) Y. Kuroda, Y. Egawa, H. Seshimo, H. Ogoshi, Chem. Lett. 1994, 23 2361-2364.

[9] For steroid-sandwiched porphyrin, see: R. P. Bonar-Law, J. K. M. Sanders, J. Chem. Soc., Chem. Commun. 1991, 574.

[10] For calixarene-sandwiched porphyrin, see: D. M. Rudkevich, W. Verboom, D. N. Reinhoudt, J. Org. Chem. 2002, 60, 6585-6587.

[11] For resorcinarene-sandwiched porphyrin, see: J. Nakazawa, J. Hagiwara, Y. Shimazaki, F. Tani, Y. Naruta, Bull. Chem. Soc. Jpn. 2012 85, 912-919.

[12] For glycoluril-sandwiched porphyrin, see: P. Thordarson, E. J. A. Bijsterveld, J. A. A. W. Elemans, P. Kasák, R. J. M. Nolte, A. E. Rowan, J. Am. Chem. Soc. 2003, 125, 1186-1187.

[13] General reviews: a) T. Koide, K. Youfu, S. Saito, A. Osuka, Chem Commun. 2009, 6047-6049; b) S. Saito, A. Osuka, Angew. Chem. Int Ed. 2011, 50, 4342-4373; c) M. Stępień, N. Sprutta, L. Latos-Grażyński, Angew. Chem. Int. Ed. 2011, 50, 4288-4340; d) T. Tanaka, A. Osuka, Chem. Rev. 2017, 117, 2584-2640; e) Y. M. Sung, J. Oh, W.-Y. Cha, W. Kim, J. M. Lim, M.-C. Yoon, D. Kim, Chem. Rev. 2017, 117, 2257-2312 f) B. Szyszko, M. J. Białek, E. Pacholska-Dudziak, L. Latos-Grażyński, Chem. Rev. 2017, 117, 2839-2909.

[14] a) T. Koide, K. Youfu, S. Saito, A. Osuka, Chem. Commun. 2009, 60476049; b) M. Stępień, B. Szyszko, L. Latos-Grażyński, J. Am. Chem. Soc 2010, 132, 3140-3152; c) W.-Y. Cha, J. M. Lim, M.-C. Yoon, Y. M. Sung, B. S. Lee, S. Katsumata, M. Suzuki, H. Mori, Y. Ikawa, H. Furuta, A Osuka, D. Kim, Chem. Eur. J. 2012, 18, 15838-15844; d) S.-I. Ishida, T. Higashino, S. Mori, H. Mori, N. Aratani, T. Tanaka, J. M. Lim, D. Kim, A Osuka, Angew. Chem. Int. Ed. 2014, 53, 3427-3431; e) K. Naoda, H. Mori, J. Oh, K. H. Park, D. Kim, A. Osuka, J. Org. Chem. 2015, 80 11726-11733.

[15] a) M. Stepień, L. Latos-Grażyński, N. Sprutta, P. Chwalisz, L. Szterenberg, Angew. Chem. Int. Ed. 2007, 46, 7869-7873; b) J. Sankar,
S. Mori, S. Saito, H. Rath, M. Suzuki, Y. Inokuma, H. Shinokubo, K. Suk Kim, Z. S. Yoon, J.-Y. Shin, J. M. Lim, Y. Matsuzaki, O. Matsushita, A Muranaka, N. Kobayashi, D. Kim, A. Osuka, J. Am. Chem. Soc. 2008 130, 13568-13579; c) M.-C. Yoon, P. Kim, H. Yoo, S. Shimizu, T. Koide S. Tokuji, S. Saito, A. Osuka, D. Kim, J. Phys. Chem. B 2011, 115, 14928-14937.

[16] K. S. Kim, Z. S. Yoon, A. B. Ricks, J.-Y. Shin, S. Mori, J. Sankar, S. Saito, Y. M. Jung, M. R. Wasielewski, A. Osuka, D. Kim, J. Phys. Chem. A 2009, 113, 4498-4506.

[17] a) S. Mori, A. Osuka, J. Am. Chem. Soc. 2005, 127, 8030-8031; b) Shigeki Mori, Soji Shimizu, A. Ryuichiro Taniguchi, A. Osuka, Inorg. Chem. 2005, 44, 4127-4129; c) Y. Tanaka, S. Saito, S. Mori, N. Aratani, H. Shinokubo, N. Shibata, Y. Higuchi, Z. S. Yoon, K. S. Kim, S. B. Noh, J. K. Park, D. Kim, A. Osuka, Angew. Chem. Int. Ed. 2008, 47, 681-684; d) H. Rath, N. Aratani, J. M. Lim, J. S. Lee, D. Kim, H. Shinokubo, A. Osuka, Chem. Commun. 2009, 3762-3764.

[18] a) V. Balzani, A. Credi, M. Venturi, Molecular Devices and Machines, WILEY-VCH Verlag GmbH, Weinheim, 2008; b) Ben L Feringa, W. R. Browne, Molecular Switches, John Wiley \& Sons, 2011.

[19] For hexaphyrins undergoing a so-called "caterpillar motion", see: a) M. Suzuki, A. Osuka, Chem. Commun. 2005, 3685-3687; b) H. Mori, N. Aratani, A. Osuka, Eur. J. Org. Chem. 2012, 2012, 1913-1919.

[20] M. Ménand, M. Sollogoub, B. Boitrel, S. Le Gac, Angew. Chem. Int. Ed. 2016, 55, 297-301.

[21] S. Le Gac, B. Boitrel, M. Sollogoub, M. Ménand, Chem. Commun. 2016 52, 9347-9350.

[22] H. Ruffin, G. Nyame Mendendy Boussambe, T. Roisnel, V. Dorcet, B Boitrel, S. Le Gac, J. Am. Chem. Soc. 2017, 139, 13847-13857.

[23] M. Suzuki, A. Osuka, Org. Lett. 2003, 5, 3943-3946.

[24] Unpublished results

[25] Although symmetrical hybrids were targeted in this paper, it is worth to note that unsymmetrical ones are accessible using two different partners

[26] S. Cho, Z. S. Yoon, K. S. Kim, M.-C. Yoon, D.-G. Cho, J. L. Sessler, D. Kim, J. Phys. Chem. Lett. 2010, 1, 895-900.

[27] H. Mori, A. Osuka, Chem. Eur. J. 2015, 21, 7007-7011.

[28] Such splitting characteristic of an exciton coupling (couplet) between the hexaphyrin and a close-lying chromophore obliquely oriented, vanished in the dumbbell conformation, may reflect the specific offset position of the rectangular hexaphyrin protruding over a benzyl group (OBn-A).

[29] Figure 3, b vs. c and d vs. e, blue frames; $\delta_{\mathrm{NH}}=3.90$ and $3.31 \mathrm{ppm}$ for CD $^{\mathrm{D}}[26] \mathrm{HCD}$ vs. $-3.50 \mathrm{ppm}$ for $\mathrm{CD}^{\mathrm{R}}[26] \mathrm{HCD}$; and $16.50 \mathrm{ppm}$ for CD'28]HCD vs. $25.76 \mathrm{ppm}$ for $\mathrm{CD}^{\mathrm{R}}$ [28]HCD).

[30] Water as catalyst was ruled out as additional experiments performed in $\mathrm{CDCl}_{3}$ saturated with $\mathrm{D}_{2} \mathrm{O}$ did not change the kinetic rate.

[31] THF- $d_{8}$ leads to faster equilibration rates at $330 \mathrm{~K}$. 


\section{Entry for the Table of Contents}

\section{FULL PAPER}

Royale with cheese. New sandwich compounds made of a hexaphyrin doubly-capped by cyclodextrins have been developed. The central hexaphyrin behaves as a dualresponsive device, coupling the cavities with different operating modes in switchable manners, depending on both its (anti)aromaticity and conformation. The accessibility of two compartmentalized-and-coupled confined spaces is locked/unlocked in a reversible way or not, opening interesting perspectives in allosteric regulation.

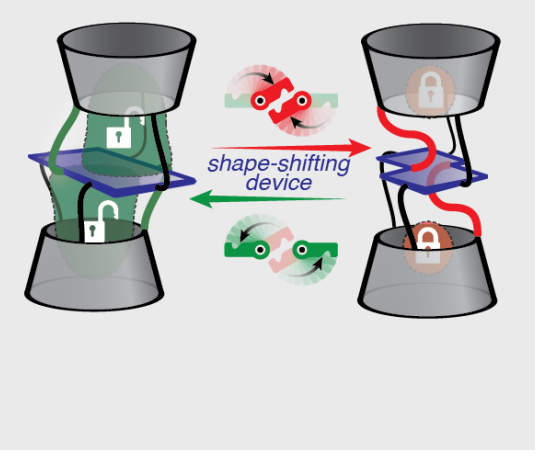

Mickaël Ménand, * Matthieu Sollogoub, Bernard Boitrel, and Stéphane Le Gac*

Page No. - Page No.

Cyclodextrin-Sandwiched Hexaphyrin Hybrids. Side-to-Side Cavity Coupling Switched by a Temperature and Redox Responsive Central Device 